\title{
Improvement on the Strength of 6063 Aluminum Alloy by Means of Warm Rolling Operation
}

\author{
Adekunle N.O. ${ }^{1, *}$, Aiyedun P.O. ${ }^{1}$, Kuye S.I. ${ }^{1}$ and Lawal I.O. ${ }^{1}$ \\ ${ }^{1}$ Department of Mechanical Engineering, Federal University of Agriculture, Abeokuta, Nigeria \\ Corresponding Author: *noadekunle@yahoo.com
}

\begin{abstract}
This paper presents the effect of varying processing variables on the superplastic ductility of $A l$ 6063 alloy. The three variables investigated were total strain, reheating time and strain rate during warm rolling (by varying the reduction per pass). The alloy samples were warm rolled at strain rates varying from $1.0 \times 10^{-5} \mathrm{~s}^{-1}$ to $4.1 \times 10^{-1} \mathrm{~s}^{-1}$ to a total true strain of 3 , at $4.4-7.5 \%$ reduction per pass for 3 hours reheating time between passes. Tensile test and microstructural analysis were carried out on the samples. The results showed that at lowest strain rate $\left(4.1 \times 10^{-3} \mathrm{~s}^{-1}\right)$, greatest ductility, fracture stress and fracture energy were achieved with $4.0 \%$ reduction pass. The material warm rolled to a total true strain of 2.9 exhibited much higher ductility. Longer reheating time revealed coarser grains, with peak ductility occurring at slower strain rates.
\end{abstract}

Keywords: Hot Work, Tensile Strength, Total Strain, Strain Rate, Reheating Time

\subsection{Introduction}

The demand for aluminum has increased rapidly, due to its unique properties that have made it one of the most versatile materials being used for engineering and construction (Chee and Mohamad, 2009). These properties include: durability, light weight, extrudability, good surface finish and corrosion resistant, at present aluminum and its alloys are used as an alternative for other metals (De Silva and Pereral, 2012).

The excellent properties of 6xxx-group alloys have made it suitable for application in the building, aircraft, and automotive industries (Mrówka-Nowotnik and Sieniawski, 2005).Through proper combination of solution heat treatment, quenching, cold working and artificial aging, very high strengths can be obtained (Esezobor and Adeosun, 2006).

The most commonly accepted characteristics of a superplastic material are: a fine, equiaxed grain structure with high angle boundaries; a deformable second phase if present; low strain rates at elevated temperatures equal to $0.5-0.7 \mathrm{Tm}$; resistance to cavitation; and a thermally stable structure (Stengall,1999). Several thermomechanical treatments have been done in which the interplay of precipitates or constituent particles with deformation to refine grain size, enhance strength, toughness and improve ductility (Sherby and Wadsworth, 2007). Thermomechanical treatment is the combination of plastic deformation and heat treatment to provide high strength properties. It can either be intermediate thermomechanical heat treatment whose deformation is applied to give very fine recrystallized grains prior to solution treatment or final thermomechanical heat treatment whose deformation is applied after solution treatment and may involve cold or warm working before, during or after ageing (Oliveira and Nice, 2004). The benefits that will be gained by controlling a 6063 aluminum alloy additions, combined with the appropriate thermomechanical process, will lead to grain size control which will be a requirement for superplastic behavior (Sherby and Wadsworth, 2007). The effect of homogenization treatment conditions on cold deformation of aluminum AA2014 and AA6063 has been studied. These aluminum alloys were homogenized at different temperature range for $8 \mathrm{~h}$ at strain rate of $2 \times 10^{-2} \mathrm{~s}^{-1}$. The secondary phases, which were large and distributed on grain boundaries became small and were spread through the grains by homogenization treatment followed by the cold deformation. The homogenization treatment improved the degree of the cold 
deformation (Totik et al., 2003). It has been observed that when aluminum alloy 6063 was processed by upset forging and cold rolling at ambient temperature, the maximum ultimate tensile strength (UTS) and hardness (HRN) increase as the range of reduction from processing increases from 0 to 50 percent. However, the ductility decreases correspondingly, which is indicative of a low strainhardening exponent (Balogun et al., 2007).

This present experimental study was designed to find out the influence of total strain, reheating time and strain rate during warm rolling on mechanical properties of structural aluminum 6063 alloys.

\subsection{Materials and Methods}

\subsection{Materials and equipment}

Materials and equipment used for this work were aluminum ingot, universal testing machine, oil-fired crucible furnace, optical microscope, roll mill and metal analyzer.

\subsection{Warm rolling operation}

Rectangular test samples of dimensions $350 \mathrm{~mm}$ x $30 \mathrm{~mm}$ × $12 \mathrm{~mm}$, were cast from AA6063 aluminum alloy ingot and melted in an oil fired crucible furnace. The melted ingot was sectioned into slabs, $2032 \mathrm{~mm}$ long with a cross section of $254 \mathrm{~mm}$ square and were solution treated above the solvus line at $615^{\circ} \mathrm{C}$ for about 5 hours and at $625^{\circ} \mathrm{C}$ for 16 hours using the procedure developed by Johnson (2005). The temperatures were monitored using two thermocouples placed on the slab surface.

All rolling was conducted utilizing a rolling mill having a maximum roll opening of $450 \mathrm{~mm}$. The slabs were warm rolled within 16 hours of upset forging into sheets in accordance with the techniques reported by Mills, (2004).

When the thermocouple indicated the desired temperature $\left(625^{\circ} \mathrm{C}\right)$, the rolling was commenced prior to the initial pass and the heating time was approximately 11 minutes. In order to maintain isothermal conditions, the slabs were reheated between passes and in the later stages of rolling, with reheating time of 3 hours. Due to the fact that the rolls were not heated on time during the rolling sequence, slabs were held under 15 seconds for each pass. The billet was heated to $625^{\circ} \mathrm{C}$ for 30 minutes to isothermal conditions prior to the first rolling pass. This was done to prevent cracking of forged slabs due to uneven heating during the rolling process. To achieve the isothermal condition the slabs were placed on a large steel plate, which acted as a heat sink in a preheated furnace. For every rolling condition used in this work, the recovery temperature was maintained at $625^{\circ} \mathrm{C}$. The temperature at which the material was stabilized just prior to rolling became the variable of interest.

A total of 5 different processes were achieved (see Table 1) by varying the percentage reduction per pass, the interpass reheating time and total true final strain. The warm rolling processing samples were lettered from A to E progressing from the least severe light reduction schedule to the most severe heavy reduction schedule. Reduction per pass of $7.5 \%$ was referred to as heavy reduction schedule while that of $4.4 \%$ was referred to as light reduction schedule.

Table 1: Warm rolling operation used for the experiment

\begin{tabular}{lccccc}
\hline Processes & $\begin{array}{c}\text { Sample A } \\
\text { For }(\mathrm{M})\end{array}$ & $\begin{array}{c}\text { Sample B } \\
\text { For }(\mathrm{M})\end{array}$ & $\begin{array}{c}\text { Sample C } \\
\text { For }(\mathrm{N})\end{array}$ & $\begin{array}{c}\text { Sample D } \\
\text { For }(\mathrm{N})\end{array}$ & $\begin{array}{c}\text { Sample E } \\
\text { For }(\mathrm{N})\end{array}$ \\
\hline \% Reduction per pass & 4.4 & 4.4 & 4.4 & 7.5 & 7.5 \\
Reheating time between passes & 3.0 & 3.0 & 4.0 & 3.0 & 3.0 \\
Total true strain & 3.0 & 3.0 & 2.9 & 2.9 & 2.9 \\
\hline
\end{tabular}

After rolling, tensile samples were produced according ASTM standard. The tensile test samples were prepared such that the test axis was parallel to the rolling direction. The tensile strength test was carried out at a speed of $30.00 \mathrm{~mm} / \mathrm{min}$ using 15 samples for product $\mathrm{M}$ and $\mathrm{N}$. 


\subsection{Microstructural examination}

Warm rolled samples were prepared for photomicrographic examination by sequential grinding using emery paper grades 80, 220, 320 and 600 micron in succession. Etching of the samples for 20 seconds was done using a mixture of dilute nitric acid (68\%), hydrofluoric acid (30\%), and sodium hydroxide (2\%). Photomicrographs of samples were taken at x 400 magnification using a CEISS ICM 405 optical microscope.

\subsection{Results and Discussion}

\subsection{Chemical analysis}

The percentage chemical composition of the constituents of the alloy samples used for both products $\mathrm{M}$ and $\mathrm{N}$ are shown in Table 2.

Table 2: Chemical composition of alloy samples $\mathrm{M}$ and $\mathrm{N}$

\begin{tabular}{lcccccccccccc}
\hline Product & $\mathrm{Mg}$ & $\mathrm{Si}$ & $\mathrm{Mn}$ & $\mathrm{Cu}$ & $\mathrm{Zn}$ & $\mathrm{Ti}$ & $\mathrm{Fe}$ & $\mathrm{Na}$ & $\mathrm{B}$ & $\mathrm{Sn}$ & $\mathrm{Pb}$ & $\mathrm{Al}$ \\
\hline $\mathrm{M}$ & 0.380 & 0.574 & 0.066 & 0.102 & 0.672 & 0.014 & 0.442 & 0.015 & 0.00 & 0.00 & 0.00 & 97.7 \\
$\mathrm{~N}$ & 0.358 & 0.617 & 0.058 & 0.095 & 0.204 & 0.031 & 0.664 & 0.004 & 0.00 & 0.00 & 0.00 & 97.9 \\
\hline
\end{tabular}

\subsection{Tensile test}

Figure 1 shows the variation of ultimate tensile strength (UTS) with the strain rates varying from $1.0 \mathrm{x}$ $10^{-5} \mathrm{~s}^{-1}$ to $4.1 \times 10^{-1} \mathrm{~s}^{-1}$ for samples $\mathrm{A}$ and $\mathrm{B}$ of product $\mathrm{M}$ and samples $\mathrm{C}, \mathrm{D}$ and $\mathrm{E}$ of product $\mathrm{N}$. It was observed that Sample E had the highest UTS value of $330 \mathrm{MPa}$ at the strain rate of $1.0 \times 10^{-5} \mathrm{~s}^{-1}$, followed by sample $\mathrm{C}$ at the strain rate of $1.0 \times 10^{-5} \mathrm{~s}^{-1}$. Sample A comes after sample $\mathrm{C}$ at the strain rate of $1.0 \times 10^{-5} \mathrm{~s}^{-1}$ followed by sample D at the strain rate of $1.0 \times 10^{-5} \mathrm{~s}^{-1}$. The sample A had the least UTS value of $120 \mathrm{MPa}$ at the strain rate of $1.0 \times 10^{-5} \mathrm{~s}^{-1}$. This describes the maximum stress that the samples can handle before breakage at the same strain rate.

Figure 1 shows the variation of ultimate tensile strength (UTS) with strain rates from $1.0 \times 10^{-5} \mathrm{~s}^{-1}$ for samples A, B, C, D and E. It can be seen from the figure that the highest UTS is associated with sample $\mathrm{E}$ followed by sample $\mathrm{C}$ with $\mathrm{A}, \mathrm{B}$, and $\mathrm{D}$ trailing behind.

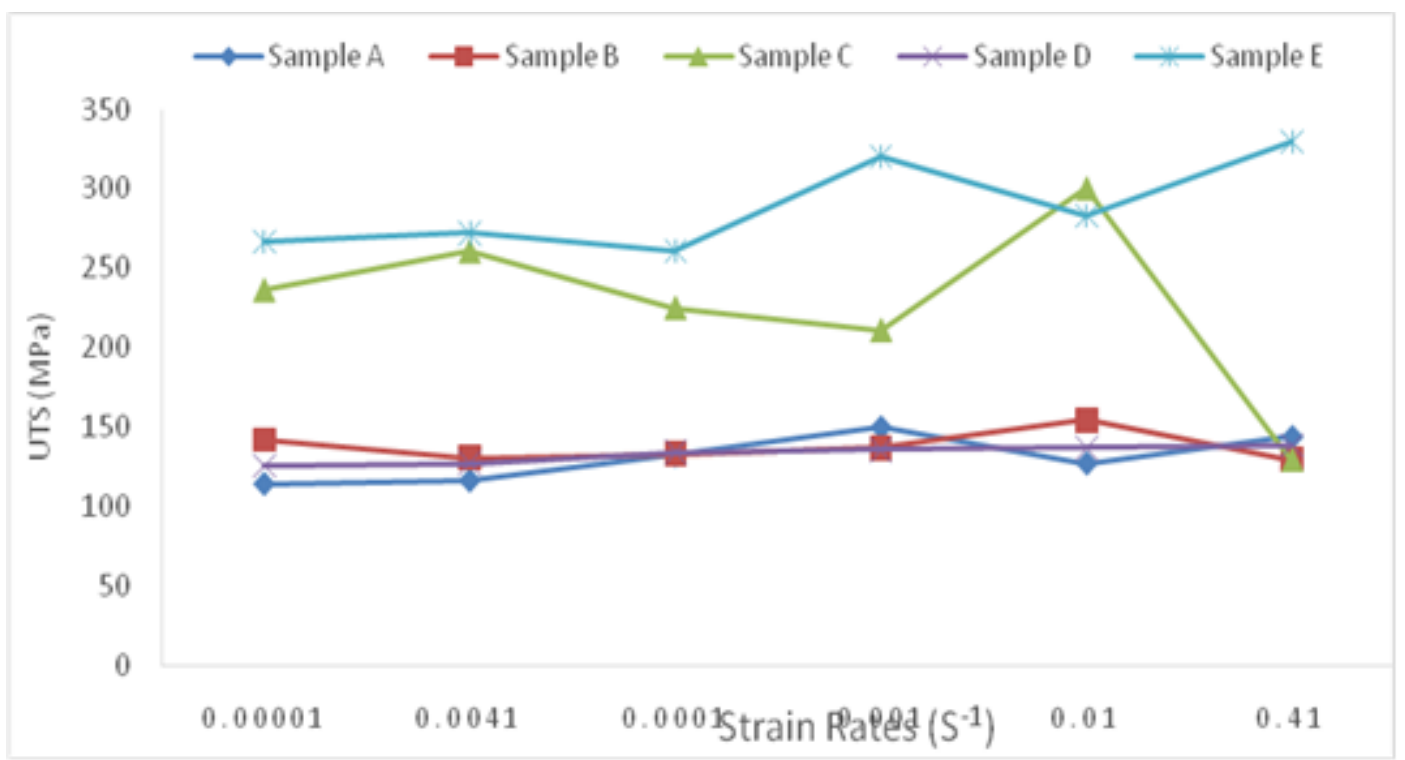

Figure 1: Ultimate tensile strength versus strain rates for tensile test conducted at $625^{\circ} \mathrm{C}$ for aluminum 6063 alloy

The graph showing the variation of yield stress versus strain rates for samples A, B, C, D and E are shown in Figure 2. It can be observed that all the samples had very low yield stress between $1.0 \times 10^{-}$ ${ }^{5}$ and $1.0 \times 10^{-4} \mathrm{~s}^{-1}$. This later rose with samples $\mathrm{C}$ and $\mathrm{E}$ having the highest yield stress compared with A, B and D. At the same strain rates considered for all the samples, samples E and C had the highest 
UTS. This describes the minimum stress under which the samples deform permanently at the same strain rate.

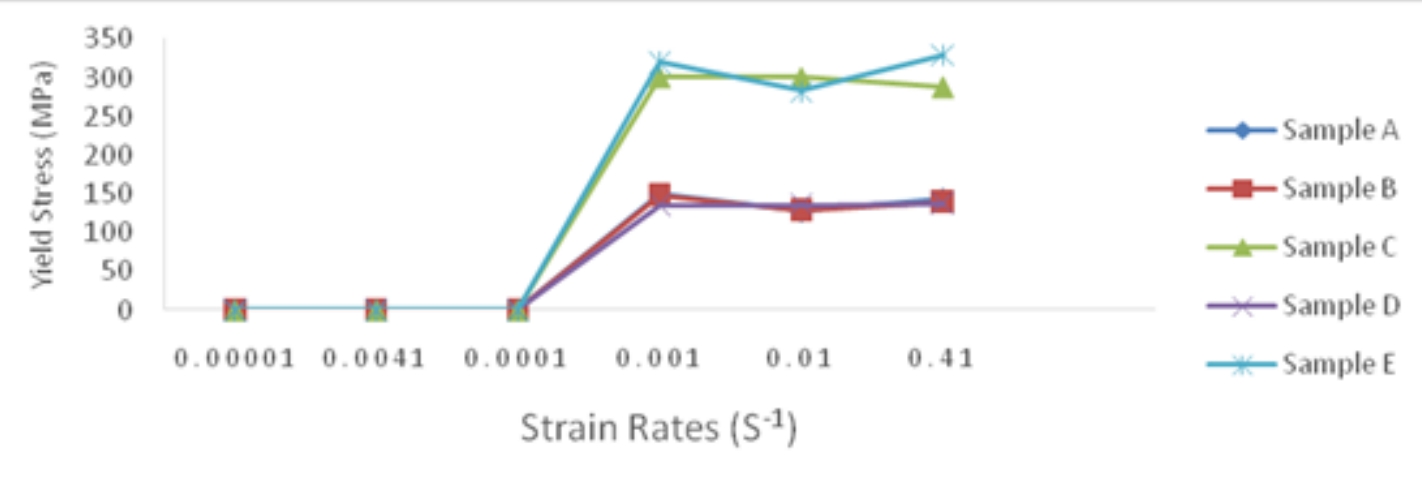

Figure 2: Yield stress versus strain rate for tensile test at $625^{\circ} \mathrm{C}$ for 6063 aluminum alloy

Variation of fracture stress with strain rates for samples A, B, C, D and E are shown in Figure 3. It can be seen that the highest fracture stress is associated with sample $\mathrm{E}$, closely followed by sample $\mathrm{C}$ with samples A, B and D having the lowest values.

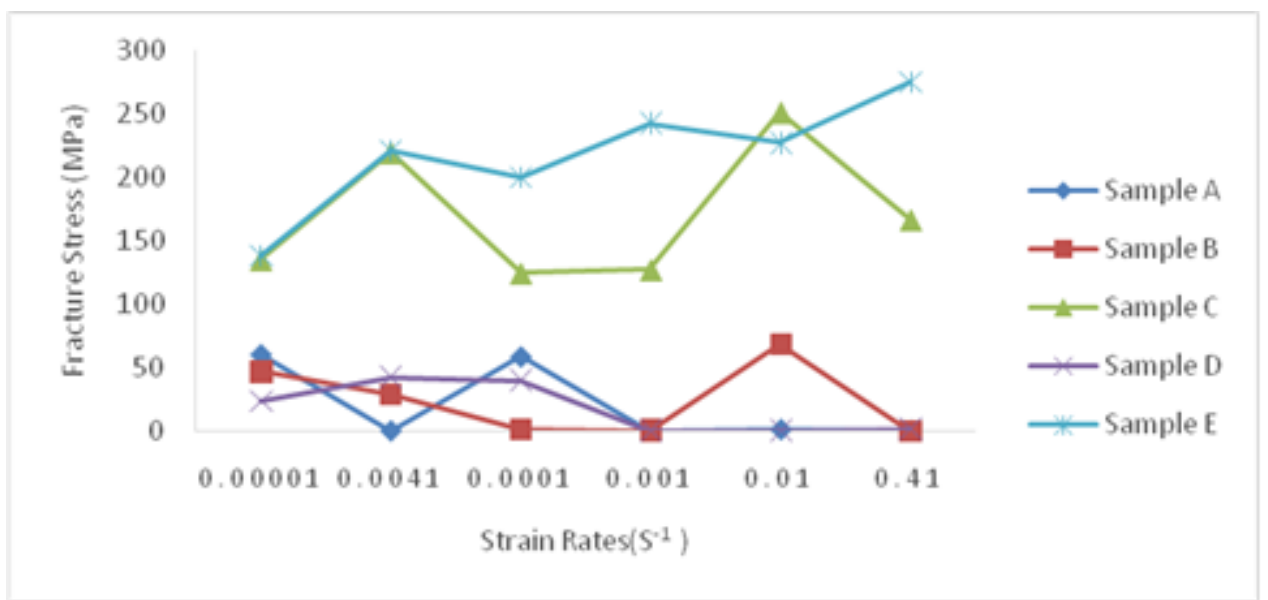

Figure 3: Fracture stress versus strain rate for tensile test conducted at $625^{\circ} \mathrm{C}$ for 6063 aluminum alloy

The graph showing the fracture energy versus strain rate for the samples being considered are shown in Figure 4. It can be observed that samples $\mathrm{E}$ again had the highest values of fracture energy, closely followed by sample $\mathrm{C}$ while those for samples A, B and D were relatively small.

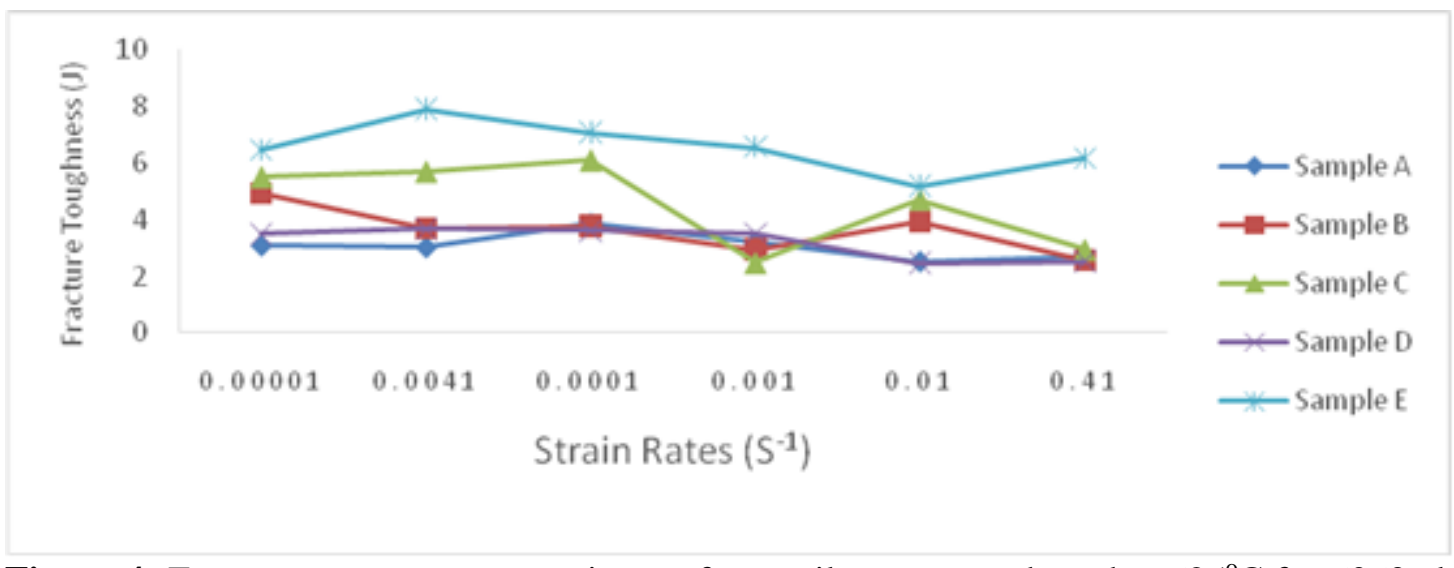

Figure 4: Fracture energy versus strain rate for tensile stress conducted at $625^{\circ} \mathrm{C}$ for 6063 aluminum alloy 
The graph showing the variation of elongation with strain rate is given by Figure 5 for samples A, B, $\mathrm{C}, \mathrm{D}$ and $\mathrm{E}$. It can be observed from the figure that sample $\mathrm{E}$ had the highest percentage elongation, closely followed as usual by sample C, with samples A, B and D trailing behind. This describes the maximum elongation of the gage length divided by the original length at the same strain rate.

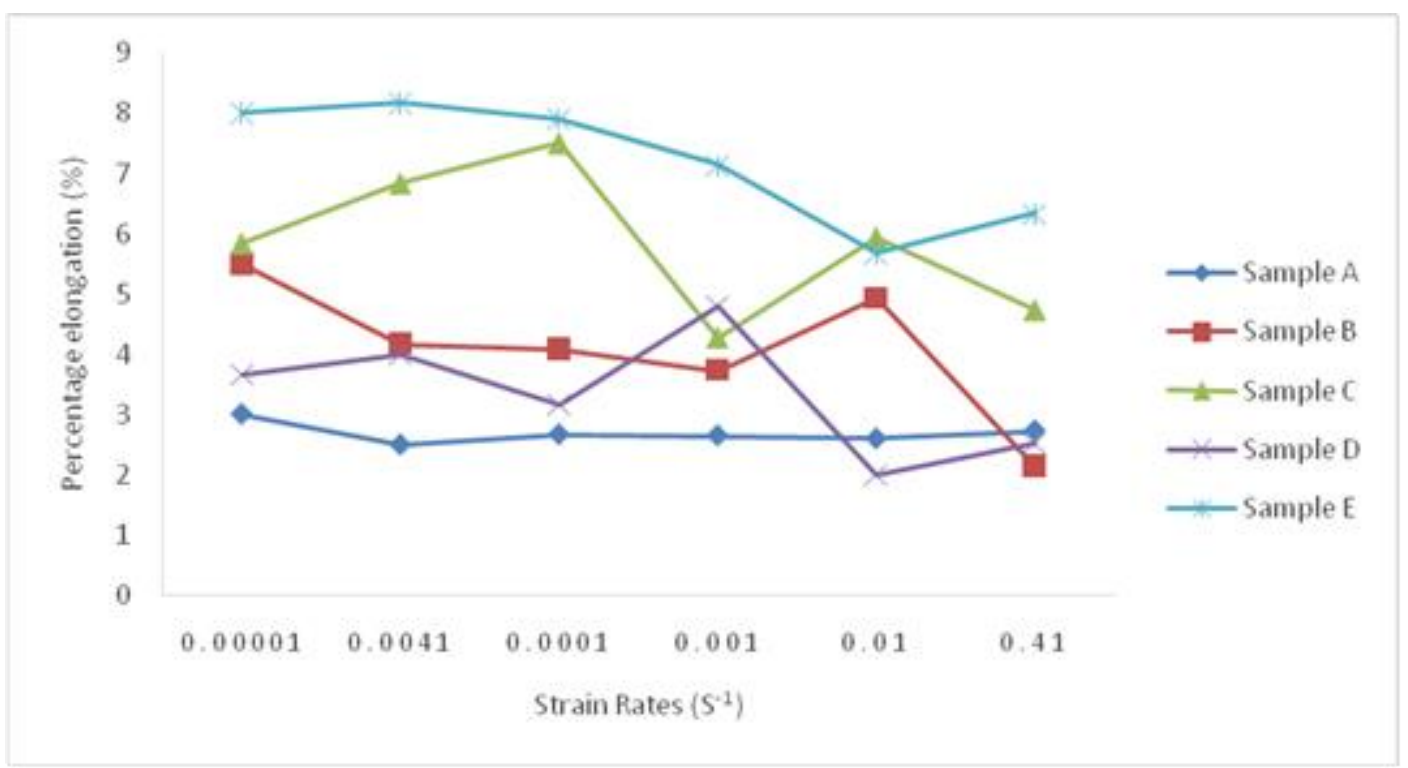

Figure 5: Percentage elongation versus strain rate for tensile test conducted at $625^{\circ} \mathrm{C}$ for 6063 aluminum alloy

Figure 5 shows maximum elongations occurring at strain rates of $1.0 \times 10^{-5} \mathrm{~s}^{-1}$ and $1.0 \times 10^{-4} \mathrm{~s}^{-1}$. This agrees with Grider, 2006. Figure 5 clearly shows that at lower strain rates a lower strength is realized and the same was observed for the other processes investigated. In comparing process A (light reduction) with process $\mathrm{B}$ (heavy reduction), shown in figure 5, process $\mathrm{A}$ is stronger than the same alloy rolled to the same total true strain of 3.0 using process B.

\subsection{Microstructural analysis}

The micrographs of the processes A-E, deformed at room temperature are shown in Plates A-J. These plates revealed fine grain structures due to grain boundary sliding. The microstructure revealed the response of the aluminum alloy when undergoing various processes during the investigation of the influence of total strain, strain rate and reheating time during warm rolling on the superplastic ductility of 6063 aluminum alloy.

Processes A and B achieved elongations of 232 and 408\%, though they had similar grain size. These microscopy results suggest a refined structure has evolved; however, if continuous re-crystallization is occurring, the short reheating may not have allowed sufficient time for a structure capable of sustaining grain boundary sliding to develop.

Process $\mathrm{C}$, shown in Plate $\mathrm{F}$ reveals that grain coarsening is beginning to appear. These grains are longer because of the longer reheat times used in Process C. An elongation of $424 \%$ was strained with this specimen.

Process $\mathrm{D}$ has a banded grain structure with a second phase uniformly distributed throughout the structure. Plate $\mathrm{G}$ and $\mathrm{H}$ shows the effect of Process D on the material. This specimen reveals a very fine beta phase that is not as uniformly distributed as in the other processes.

Process E is illustrated in Plates I and J, and shows a coarser second phase that is also more uniformly distributed than in Process E. 
Product M:

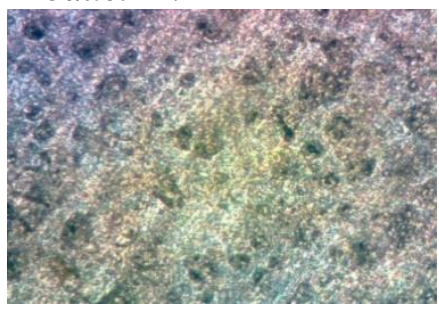

Plate A: As-received (x400)

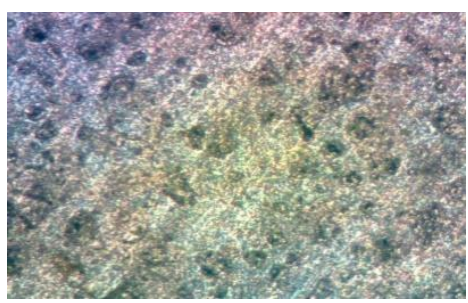

Plate C: After warm rolling using Process B (x400) in transverse direction

\section{Product $N$ :}

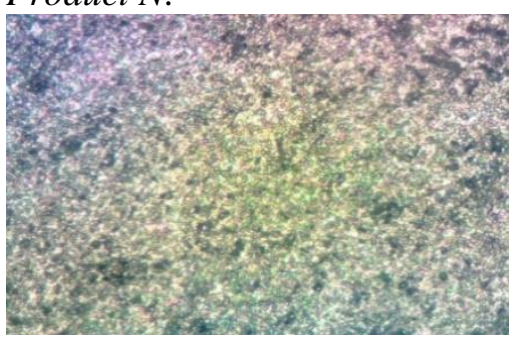

Plate E: As-received (x400)

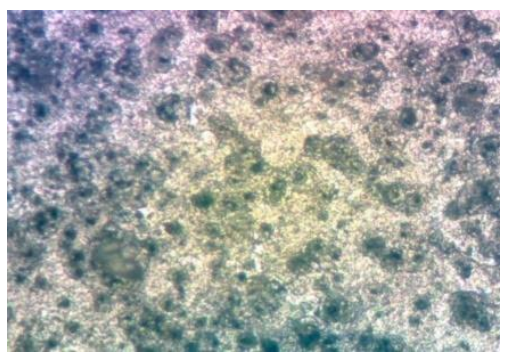

Plate G: After warm rolling using Process D (x400) in transverse direction

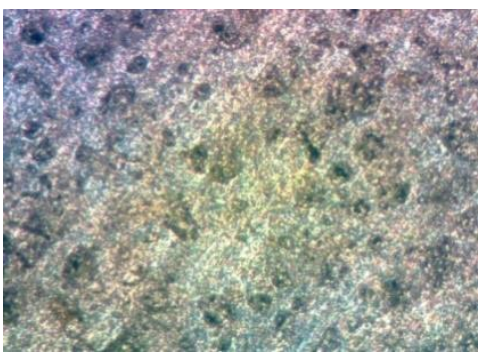

Plate I: Hot working at $625^{\circ} \mathrm{C}$ using Process $\mathrm{E}(\mathrm{x} 400)$

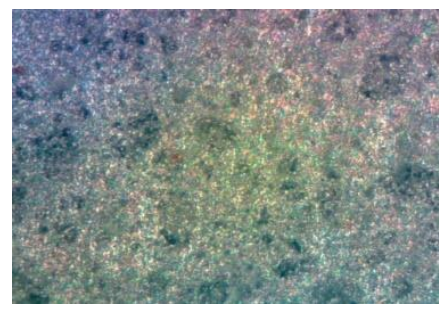

Plate B: Process A tensile tested at room temp. $(\mathrm{x} 400)$

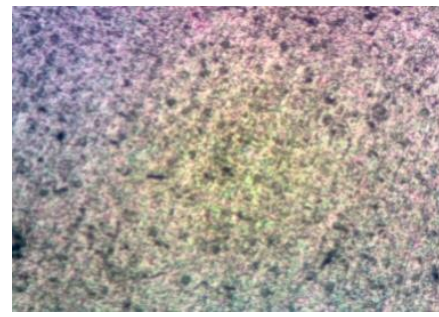

Plate D: After warm rolling using Process $\mathrm{B}$ (x400) in longitudinal direction

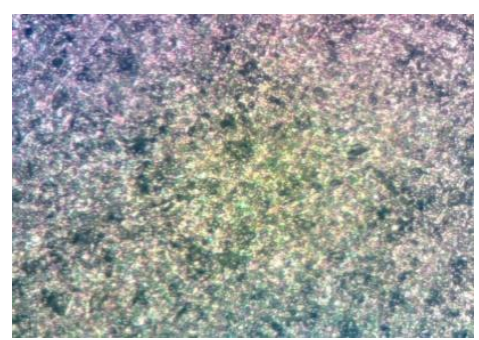

Plate F: Process $\mathrm{C}$ tensile tested at room temp. (x400)

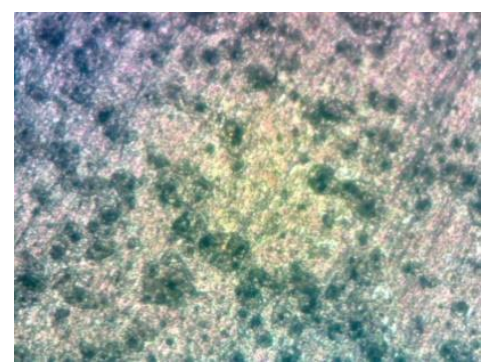

Plate H: After warm rolling using Process $\mathrm{D}(\mathrm{x} 400)$ in longitudinal direction

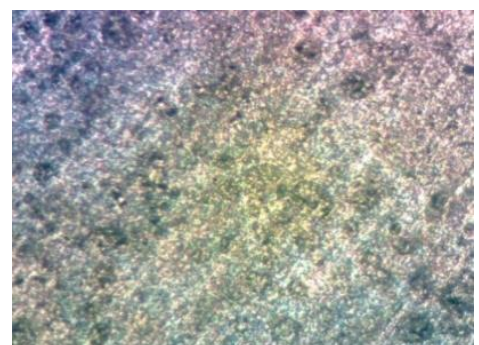

Plate J: Taken near fracture point of Process E (x400) 


\subsection{Warm rolling}

\subsubsection{Total strain (2.9 vs 3.0)}

Thermomechanical Process A and B, as shown in Table 1 involved warm rolling to nominal true strain of 2.9, while Processes C, D and E represented a nominal true strain of 3.0. Overall, the more severely worked material (Processes Band C) exhibited much higher warm-temperature ductility than the material strained to 3.0. As shown in Figure 4, Processes B and C resulted in peak ductility of $5.55 \%$ and $5.8 \%$, respectively; while Processes D and E showed peak ductility of $3.7 \%$ and $8.0 \%$ respectively. Process A yielded the lowest ductility of 3.0\%.

The cause of low ductility was believed at first to be from damaged particles resulting from heavy reduction per pass during the warm rolling phase of Process A. These cracked particles would become void initiation sites which could cause premature fracture and hence low ductility. Increased reduction per pass and short reheat times likely resulted in a higher dislocation density, possibly less precipitate and lessened extent of continuous recrystallization, i.e. insufficient misorientation between adjacent grains for boundary sliding. Figure 3 shows that the material used in Process A is stronger and less ductile. Further study is required in this area.

\subsubsection{Strain rate (Light reduction versus Heavy reduction)}

Process A and B were warm rolled to a total nominal strain of 3.0 with Process A being the light reduction schedule and Process $B$ the heavy reduction schedule. Figure 1 shows that at lower strain rates $\left(1.0 \times 10^{-5} \mathrm{~s}^{-1}\right)$ Process $\mathrm{B}$ appears to be strain hardening to a greater extent. This suggests increased coarsening. At higher strain rates $\left(4.1 \times 10^{-1} \mathrm{~s}^{-1}\right)$, Process A strain harden at higher rates than B.

The heavily reduced material (Process B) at lower strain rate is strain hardening faster than Process A because more stored energy is present, causing the grains to grow out faster and coarsen. This could be one reason why Process A has low ductility. In the case of Process C, D and E the same results were observed except that overall flow stress values were higher than for Process A and B.

\subsubsection{Reheating time ( 2 hours versus 3 hours)}

Process B was warm rolled with a 2 hours reheat time per pass and Process $C$ was warm rolled with a 3 hours reheat time per pass. Longer reheating times as compared to shorter reheating time revealed coarser grains, peak ductility occurring at higher strain rates, and similar $m$ values. Figure 1, clearly shows higher $\mathrm{m}$ values for Process A, B and D at the higher strain rates of $4.1 \times 10^{-1} \mathrm{~s}^{-1}, 1.0 \times 10^{-2} \mathrm{~s}^{-1}$ and $4.1 \times 10^{-1} \mathrm{~s}^{-1}$ respectively. Process $\mathrm{C}$ and Process $\mathrm{E}$ had their highest $m$ values at strain rates of 1.0 $\times 10^{-2} \mathrm{~s}^{-1}$ and $4.1 \times 10^{-1} \mathrm{~s}^{-1}$ respectively.

\subsection{Conclusion}

The study investigated the effects of hot working on 6063 aluminum alloy. The study conducted revealed that hot working of 6063 aluminum alloy impacts significant effects on its mechanical properties. Longer reheating times as compared to shorter reheating time revealed coarser grains, peak ductility occurring at higher strain rates, and similar values. Based on the results obtained, the study confirmed that the greatest superplastic ductility were achieved in material experiencing the largest total strain, lowest strain rate and most prolonged reheating time during warm rolling.

\section{References}

Balogun, S., Esezobor, D. \& Adeosun, S. (2007). Effects of Deformation Processing on the Mechanical Properties of Aluminum Alloy 6063. Metallurgical and Materials Transactions A, 38(7), 1570-1574.

Chee Fai Tan \& Mohamad R. Said (2009). Effect of Hardness Test on Precipitation Hardening Aluminium Alloy 6061-T6. Chiang Mai J. Sci., 36(3), 276-286. 
De Silva, G. I. P. \& Pereral, W. C. (2012). Improvement of the Mechanical properties of Aluminum 6063 T5 Extrudates by Varying the Aging Condition Cost-effectively. In: Procs SAITM Research Symposium on Engineering Advancements, 62-64.

Esezobor D. E. \& Adeosun S. O. (2006). Improvement on the Strength 6063 Aluminum Alloy by Means of Solution Heat. Treatment Materials Science and Technology (MS\&T) PROCESSING

Grider, W.J. (2006). The Effect of Thermomechanical Processing Variables on Ductility of a HighMg, Al-Mq-Zr Alloy. M.S. Thesis, Naval Postgraduate School, Monterey, California.

Johnson, R.B. (2005). Effect of Thermomechanical Processing on the Elevated Temperature Behaviour of Lithium-Containing High Mg, Al-Mg Alloys. M.S. Thesis, Naval Postgraduate School, Monterey, California.

Mills, J.G. (2004). Tensile Deformation Behaviour of Aluminium Alloys at Warm Forming Temperatures. Materials Science and Engineering A, 352(1-2), 279-286.

Mrówka-Nowotnik G. \& Sieniawski, J. (2005). Influence of Heat Treatment on the Microstructure and Mechanical Properties of 6005 and 6082 Aluminium Alloys. In: Procs 13th Scientific International Conference on Achievements in Mechanical and Materials Engineering, 447-450.

Oliveira, C. V. \& Nice, M. (2004). Investigation of Mechanical Properties and Grain Structure of 5xxx Aluminum Alloys under Precisely Controlled Annealed Conditions. International Journal of Scientific and Research Publications, 3(1), 1-4.

Sherby, O. D. \& Wadsworth (2007). Development and Characterization of Fine-Grain Superplastic Materials Deformation. Processing and Structure, 354-384.

Stengall, M.J. (1999). Cavitation in Superplasticity Superplastic Forming of Structure Alloys. In: Procs TMS-AIME, 321-336.

Totik, Y., Sadeler, R., Kaymaz, I. \& Gavgali, M. (2003). The Effect of Homogenization Treatment on Cold Deformations of AA 2014 and AA 6063 Alloys. Journal of Materials Processing Technology, $147,60-64$. 